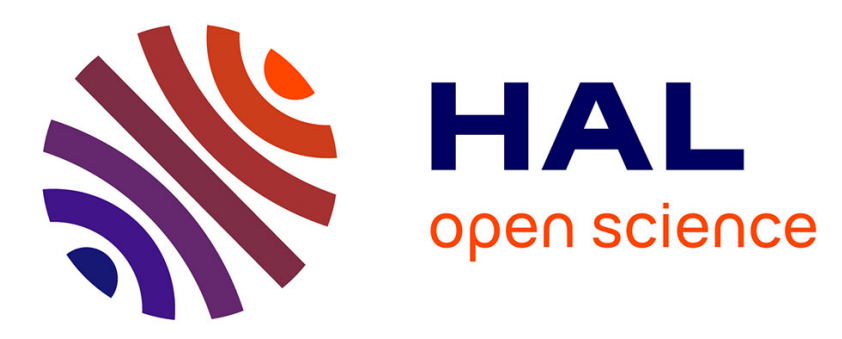

\title{
The effect of health care expenditures on survival in locally advanced and metastatic Non Small Cell Lung Cancer
}

Lionel Perrier, Magali Morelle, Nathalie Havet, Anthony Montella, Bertrand Favier, David Pérol, Frédéric Gomez, Marie-Odile Carrère, Paul Rebattu

\section{To cite this version:}

Lionel Perrier, Magali Morelle, Nathalie Havet, Anthony Montella, Bertrand Favier, et al.. The effect of health care expenditures on survival in locally advanced and metastatic Non Small Cell Lung Cancer. 2009. halshs-00371825

\section{HAL Id: halshs-00371825 \\ https://shs.hal.science/halshs-00371825}

Submitted on 30 Mar 2009

HAL is a multi-disciplinary open access archive for the deposit and dissemination of scientific research documents, whether they are published or not. The documents may come from teaching and research institutions in France or abroad, or from public or private research centers.
L'archive ouverte pluridisciplinaire HAL, est destinée au dépôt et à la diffusion de documents scientifiques de niveau recherche, publiés ou non, émanant des établissements d'enseignement et de recherche français ou étrangers, des laboratoires publics ou privés. 
The effect of health care expenditures on survival in locally advanced and metastatic Non Small Cell Lung Cancer

Lionel Perrier, Magali Morelle, Nathalie Havet, Anthony Montella, Bertrand Favier, David Pérol, Frédéric Gomez, Marie-Odile Carrère, Paul Rebattu

GATE Groupe d'Analyse et de Théorie Économique UMR 5824 du CNRS

93 chemin des Mouilles - 69130 Écully - France

B.P. $167-69131$ Écully Cedex

Tél. +33 (0)4 72866060 - Fax +33 (0)4 72866090

Messagerie électronique gate@gate.cnrs.fr

Serveur Web : www.gate.cnrs.fr 


\title{
The effect of health care expenditures on survival in locally advanced and metastatic Non Small Cell Lung Cancer
}

\author{
Lionel Perrier $^{\mathrm{a}}$, Magali Morelle ${ }^{\mathrm{b}}$, Nathalie Havet ${ }^{\mathrm{c}}$, Anthony Montella ${ }^{\mathrm{d}}$, Bertrand Favier ${ }^{\mathrm{e}}$, \\ David Pérol ${ }^{\mathrm{f}}$, Frédéric Gomez ${ }^{\mathrm{g}}$, Marie-Odile Carrère ${ }^{\mathrm{h}}$, Paul Rebattu ${ }^{\mathrm{i}}$
}

${ }^{a}$ University of Lyon, Lyon, F-69003, France; University of Lyon 2, Lyon, F-69007, France; University of Lyon 1, Lyon, F-69003, France; CNRS, UMR 5824, GATE, Ecully, F-69130, France; ENS LSH, Lyon, F-69007, France; Centre Leon Bérard, Lyon, F-69003, France. Mail: perrierl@lyon.fnclcc.fr

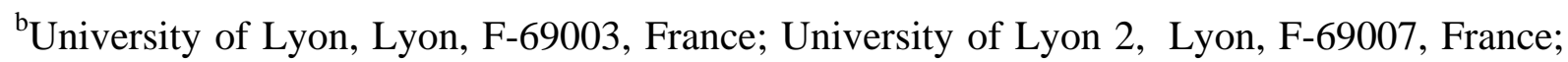
University of Lyon 1, Lyon, F-69003, France; CNRS, UMR 5824, GATE, Ecully, F-69130, France; ENS LSH, Lyon, F-69007, France; Centre Leon Bérard, Lyon, F-69003, France. Mail: morelle@lyon.fnclcc.fr

${ }^{\mathrm{c}}$ University of Lyon, Lyon, F-69003, France; University of Lyon 2, Lyon, F-69007, France; University of Lyon 1, Lyon, F-69003, France; CNRS, UMR 5824, GATE, Ecully, F-69130, France; ENS LSH, Lyon, F-69007, France; Centre Leon Bérard, Lyon, F-69003, France. Mail: havet@gate.cnrs.fr

${ }^{\mathrm{d}}$ University of Lyon; Cancer Centre Léon Bérard, department of biostatistics, 28 rue Laënnec, 69373 Lyon Cedex 08, France. Mail: montella@lyon.fnclcc.fr 
${ }^{\text {e} U n i v e r s i t y ~ o f ~ L y o n ; ~ C a n c e r ~ C e n t r e ~ L e ́ o n ~ B e ́ r a r d, ~ p h a r m a c y, ~} 28$ rue Laënnec, 69373 Lyon Cedex 08, France. Mail: favier@lyon.fnclcc.fr

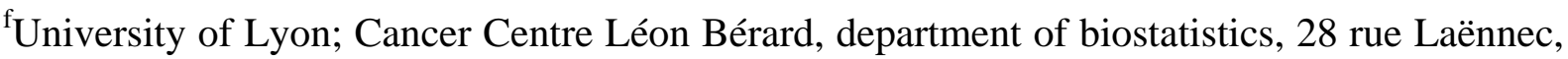
69373 Lyon Cedex 08, France. Mail: perold@lyon.fnclcc.fr

${ }^{\text {g}}$ University of Lyon; Cancer Centre Léon Bérard, department of medical information, 28 rue Laënnec, 69373 Lyon Cedex 08, France. Mail: gomez@lyon.fnclcc.fr

${ }^{\text {h}}$ University of Lyon, Lyon, F-69003, France; University of Lyon 2, Lyon, F-69007, France; University of Lyon 1, Lyon, F-69003, France; CNRS, UMR 5824, GATE, Ecully, F-69130, France; ENS LSH, Lyon, F-69007, France; Centre Leon Bérard, Lyon, F-69003, France. Mail: mo.carrere@wanadoo.fr

${ }^{\mathrm{i}}$ University of Lyon; Cancer Centre Léon Bérard, department of medical oncology, 28 rue Laënnec, 69373 Lyon Cedex 08, France. Mail: rebattu@lyon.fnclcc.fr 


\section{Summary}

Context: The significant survival benefit of chemotherapy over best supportive care for locally advanced and metastatic NSCLC has been amply demonstrated in the literature. However, there is no clear evidence of the impact of the type of chemotherapy or of a superiority of combination chemotherapy over single-agent chemotherapy.

Objective: The present study empirically examines, in real-life practise and using multiple proxies, the impact of health care expenditures on overall survival in locally advanced and metastatic NSCLC in order to guide medical decision-making.

Methods: Disease characteristics, the resources used, the costs of treatment and survival data were retrospectively collected from the records of 175 patients treated between 2000 and 2004 at Léon Bérard Regional Cancer Center (Lyon, France). Survival data were modelled using multivariate Cox models and controlled for endogeneity with the instrumental variable method.

Results: The median survival for the whole cohort was 289 days. The average total cost of treatment reached $€ 35,160$. Survival was significantly shorter for patients with stage IV disease, poor performance status, and past or concomitant cardiovascular disease and/or diabetes, for current smokers, and for patients with adenocarcinoma compared to large cell carcinoma. Survival duration was not significantly associated with the total cost of treatment per day of hospitalisation, the number of chemotherapy drugs administered, nor inpatient length of stay.

Conclusion: Higher care expenditures do not appear to improve survival for patients with locally advanced or metastatic NSCLC. Hence, maintaining patient quality of life and tailoring therapy to stage, histology and comorbidities appears to be the less bad choice.

Key-words: Cost, NSCLC, Oncology, Survival

JEL code: I12 -health Production; I18 - Government Policy; Regulation; Public Health 


\section{INTRODUCTION}

At the macro-level, increased health care expenditure implies increased benefits for the patients (Cremieux et al., [1999]). However, this has not yet proven true at the micro-level. Since the demonstration by Cochrane et al. that indicators of health care inputs are generally not associated with outcomes (Cochrane et al., [1978]), the failure to identify a relationship between health care expenditure and health outcomes has become a persistent theme in the literature. Socioeconomic factors are recognized to be highly associated with health outcomes (Nolte and Mc Kee, [2004]; Young, [2001]; Saint Leger, [2001]). Lichtenberg has shown that cancers for which the stock of drugs increases more rapidly tend to have greater increases in survival rates, and the development of new cancer drugs generally increases the life expectancy of people diagnosed with cancer (Lichtenberg, [2004]). Martin et al. have shown that health care expenditure has a strong positive effect on outcomes (Martin et al., [2007]). They have found that a one percent increase in expenditure per head induces, ceteris paribus, a $0.38 \%$ reduction in years of life lost from cancer.

The present study focuses on the "real life" situations (as opposed to clinical trials) of patients with advanced or metastatic Non Small Cell Lung Cancer (NSCLC). NSCLC accounts for approximately $85 \%$ of all lung cancer cases, mostly late stage diseases with poor survival prognosis (Cella et al., [2000]; Burdett et al., [2008]).

Indeed, patients with locally advanced NSCLC are not candidates for surgery, their median survival is less than one year (Galetta et al., [2002]), and their 5-year survival rate is less than $5 \%$. The modest survival rates, high toxicities, and high costs of treatment due to multiple chemotherapy regimens have prompted investigators to examine the potential benefits of new drugs. Clinical trials generally show that chemotherapy can improve survival, as compared to best supportive care, in stage IIIB and IV NSCLC (Hensing et al., [1999]; Thongprasert et al., [1999]; Cullen et al., [1999]; Burdett et al., [2008]; Berhoune et al., [2008]). Economic studies 
have also shown that chemotherapy drugs are generally cost effective, as compared to best supportive care (Carlson et al., [2008]). However, increasing the number of chemotherapy prescriptions, prolonging cytotoxic therapy, and using innovative and expensive chemotherapy drugs do not seem to improve overall survival (Socinsky et al., [2003]; Pujol et al., [2005]; Rubio-Terrés et al., [2002]; Burdett et al., [2008]; Gridelli et al., [2007]).

In this context, and with the objective of guiding medical decision-making, we conducted a real-life practice study, based on retrospective data, to analyze the effects of health care expenditures on survival for patients with advanced NSCLC.

\section{MATERIAL AND METHODS}

\section{Inclusion and exclusion criteria}

All patients with stage IIIB or IV NSCLC treated with chemotherapy at the regional cancer centre of Lyon, France, between January 1, 2000 and December 31, 2004 were included in the study. Patients starting chemotherapy in another hospital, those receiving radiosensitizing chemotherapy alone, and those with stage I, II, or IIIA NSCLC were excluded from the study.

\section{Data source}

All data related to the characteristics of the patients and the resources used $\left(\operatorname{LOS}_{c, i}, \operatorname{LOS}_{r, i}\right.$, $\left.\operatorname{LOS}_{o, i}, q_{m_{i}}, q_{s, i}\right)$ were extracted from patient records kept by the Cancer Centre. The costs of irradiation sessions $\left(c_{s}\right)$ were obtained from the "Classification Commune des Actes Médicaux" (CCAM), the costs of hospitalisation $\left(c_{h}\right)$ were calculated by the accounting 
department of the Cancer Centre, and the price of chemotherapy drugs $\left(p_{m}\right)$ was given by the pharmacy of the Cancer Centre.

\section{Patient characteristics}

We collected data on patient age and sex, smoking habits, performance status (PS), significant weight loss (10\% of total body weight or more), as well as disease stage (IIIB versus IV) and histology (adenocarcinoma versus epidermoid or malpighian carcinoma versus large cell carcinoma). Past or concomitant cardiovascular disease and/or diabetes were also noted.

\section{Health outcomes}

The indicator used to evaluate treatment efficacy was overall survival from the date of diagnosis.

\section{Cost evaluation}

Costs were calculated from the hospital's point of view. The time horizon ranged from diagnosis to death (or August 2008 for living patients). Estimates were based on 2006 prices and costs. The total cost of treatment $\left(C T_{i}\right)$ for patient $i$ was defined as follows:

$$
C T_{i}=C c_{i}+C r_{i}+C o_{i}
$$

with $C c_{i}, C r_{i}$, and $C o_{i}$ the total costs of chemotherapy, radiotherapy, and other cares (e.g. palliative care) for patient $i$, defined as follows:

$$
\begin{gathered}
C c_{i}=\sum_{m_{i}=1}^{n}\left(q_{m_{i}} \times p_{m}\right)+\left(\operatorname{LOS}_{c, i} \times c_{h}\right) \\
C r_{i}=q_{s_{i}} \times c_{s}+\left(\operatorname{LOS}_{r, i} \times c_{h}\right) \\
C o_{i}=\operatorname{LOS}_{o, i} \times c_{h}
\end{gathered}
$$


with a chemotherapy drug $m$ administered in quantity $q_{m}$ to patient $i$, and with $p_{m}$ the unit price of the drug. The length of stay related to chemotherapy for patient $i\left(\operatorname{LOS}_{c, i}\right)$ covers all hospitalisations that included a DRG code $17 \mathrm{M} 06 \mathrm{~V}$ or 17M06W or a principal diagnosis code of aplasia for drugs (D61.1) or anaemia for drugs (D64.2) according to the International Classification of Diseases (ICD); $c_{h}$ corresponds to the daily unit cost of hospitalisation including expenses of staff, depreciation of equipment and building, costs of transfusions and drugs (except chemotherapy); $q_{s, i}$ is defined as the number of irradiation sessions for patient $i$, and $c_{s}$ as the unit cost of a session including preparation. The inpatient length of stay related to radiotherapy for patient $i\left(\operatorname{LOS}_{r, i}\right)$ covers all hospitalisations with the DRG code 17K04Z; $\operatorname{LOS}_{o, i}$ covers all hospitalisations related to other care activities. To avoid a possible confounding time effect, the total cost of treatment per day of hospitalisation for patient $i$, $C T_{i}^{d}$, was assessed such as:

$$
C T_{i}^{d}=\frac{C T_{i}}{\operatorname{LOS}_{c, i}+\operatorname{LOS}_{r, i}+\operatorname{LOS}_{o, i}}
$$

We also determined the total cost of chemotherapy per cure, $C c_{i}^{c}$ such as:

$$
C c_{i}^{c}=\frac{C c_{i}}{q_{c_{i}}}
$$

where $q_{c_{i}}$ is the number of chemotherapy cures for patient $i$.

And the total cost of radiotherapy per session:

$$
C r_{i}^{s}=\frac{C r_{i}}{q_{s_{i}}}
$$

\section{Proxies of health care expenditures}

Seven proxies were retained in this study, i.e. inpatient length of stay; number of outpatient 
health care procedures; number of chemotherapy drugs administrated; number of expensive and innovative chemotherapy drugs administrated (i.e. reimbursed by the French National Health Insurance in excess of DRG tariffs), number of irradiation sessions; total cost of chemotherapy drugs; total cost of treatment per day of hospitalisation $C T_{i}^{d}$.

\section{Statistical and econometric analyses}

\section{Descriptive statistics}

Mean and standard deviation for continuous variables, and percentage for categorical variables were used to analyze patient characteristics, the resources used (e.g. number of chemotherapy drugs administered, inpatient length of stay), and the costs of treatment. Survival time was calculated from the date of diagnosis until the date of death or the date of the last follow-up when patients were still alive (survival time was in this case therefore censored). Univariate survival analyses were performed by calculating Kaplan-Meier estimates. Differences between survival distributions were tested using log-rank statistics.

\section{Multivariate analyses}

Several expenditure indicators (logarithm of the total cost of treatment per day of hospitalisation, $C T_{i}^{d}$, number of chemotherapy drugs administered, inpatient length of stay), and survival data were modelled using multiple regression analyses. Since health care spendings and survival were jointly determined, expenditures were predictive of survival and conversely. Due to this bi-directional relationship, we could suspect a risk of endogeneity (Gujarati, [2005]; Greene, [2003]). Without any control for endogeneity, estimates from a standard Cox proportional hazard model for survival on the one hand, and from Ordinary Least Squares (OLS) for health expenditures models on the other hand, could be biased and inconsistent. Therefore we controlled endogeneity using the instrumental variable approach. 
The choice of the appropriate instrument(s) was based on data from the medical literature, practising oncologists' expertise and on our intermediate results. For all analyses, statistical significance was set at 5\%. Calculations were performed using Stata 10.0 software.

\section{RESULTS}

\section{Descriptive statistics}

Characteristics of patients

Main patient characteristics are described in table I. The sample consisted of a cohort of 175 patients of whom $73 \%$ were male. Mean age at inclusion was 60 years. A vast majority of patients (79\%) had stage IV tumours. Adenocarcinoma was the main histological group (47\% of the patients), followed by epidermoid or malpighian carcinoma (23\%), and large cell

carcinoma (30\%). In total, 124 patients were current or former smokers (71\%), 21 (12\%) had concomitant or past cardiovascular disease and/or diabetes, and 35 (20\%) reported significant weight loss. The prevalence of poor performance status was high (63\% of the patients), with $37 \%$ of the patients scoring 2 or 3.

\section{Health outcomes}

At the time of the analysis (at least four years after diagnosis), 168 patients (96\%) had died. The median survival for the whole cohort was 289 days (95\% Confidence Interval; [230-339 days]).

\section{Proxies of health expenditures}

Inpatient length of stay varied from 0 to 139 days. The median length of stay reached 25 days, with $10 \%$ of the patients staying three days or less and $90 \% 62$ days or less. The number of 
outpatient health care procedures varied from 0 to 87, with a median of seven. Ten percent of the patients never received outpatient care, whereas $90 \%$ came for 24 visits or less. The number of chemotherapy drugs administered varied from 0 to 8 . A majority of patients received between 2 and 4 drugs. Amongst the patients receiving chemotherapy, 2\% did not receive expensive and innovative drugs, i.e. chemotherapy drugs reimbursed by the French National Health Insurance in excess of DRG tariffs, and a majority received one drug of the formulary. $76 \%$ received radiotherapy with a median number of sessions of 14 [Table II]. Mean cost of chemotherapy drugs reached 4,596€, ranging from 0 to 42,705€. Mean total cost of treatment per day of hospitalisation reached $934 €$, ranging from $732 €$ to $1,715 €$ [Table III].

\section{Other costs evaluation}

The average total cost of treatment for patients with advanced or metastatic NSCLC $(\overline{C T})$ reached $€ 35,160$ ( $n=174)$, ranging from $€ 5,602$ to $€ 131,227$. The average total cost of chemotherapy ( $\overline{C_{c}}$ ) reached $€ 14,741$, i.e. $42 \%$ of $\overline{C T}$. The average total cost of radiotherapy

$\left(\overline{C_{r}}\right)$ was $€ 1,741$, i.e. $5 \%$ of $\overline{C T}$. However, as shown in table II, the average cost of radiotherapy for the 76 patients concerned reached $€ 4,008$. Results are detailed in table III.

\section{Univariate analysis of survival}

The median survival time was 8.0 months for men (CI 95\%: [7.4; 10.0]) and 11.6 months for women (CI 95\%: [9.6; 15.0]). The survival rate at 1 year was 36\% for men and $47 \%$ for women. However, the overall survival of patients was not statistically different between sexes $(p=0.06)$. The overall survival of patients younger than 70 years did not differ significantly from that of patients aged 70 and over $(\mathrm{p}=0.10)$. The overall survival of patients with $\mathrm{PS} \leq 1$ was significantly higher than that of patients with PS $>1(p=0.0003)$. The median survival time was 11.7 months for patients with PS $\leq 1$ (CI 95\%: [8.2; 14.8]), versus 7.6 months for 
patients with PS > 1 (CI 95\%: [5.7; 9.5]). The survival rate at 1 year was $47 \%$ for patients with PS 1 and $\leq 25 \%$ for patients with PS $>1$. The overall survival of patients was significantly higher for patients treated in combination with radiotherapy $(p=0.04)$. The median survival time was 7.7 months (CI 95\%: [6.7; 10.0]) for patients not treated with radiotherapy (33\% survival at 12 months) and 11.6 months (CI 95\%: [9.5; 15.0]) for patients treated (46\% survival at 12 months). The Kaplan Meier survival curve stratified by stage (IIIB and IV) (log-rank $\mathrm{p}=0.1298$ ) is presented in figure 1.

\section{Multivariate analysis of survival}

Results obtained with final survival models using instrumental variable analysis are provided in table IV. As mentioned above, modelling the interdependence between survival and expenditures may cause endogeneity problems and biased estimates. These problems could be overcome by using instrumental variables. The accuracy of the method relies on the relevance and validity of the instrumental variables available. An instrumental variable does not itself belong in the explanatory equation (here, does not have a direct effect on survival) for identification reason and must satisfy two requirements: (i) it must be strongly (or at least not weakly) correlated with the included endogenous variable (here, expenditures) conditional on the other covariates and (ii) it cannot be correlated with the error term in the explanatory equation (Greene, [2003]; Gujarati, [2005]). According to medical literature and to medical practice, age could be a valuable instrument in our context, and an age limit of 70 years would have clinically relevant distinctive value. Indeed, several surveys have shown that the intensity of cancer treatments is usually reduced for elderly patients (Gridelli et al., [2005]). These patients are generally more vulnerable to the toxicity of combined chemo- and radiation therapies, so we expected to find a negative correlation between higher age and overall 
treatment expenditures. In contrast, age was not expected to be a predictor of survival. Even if there is currently no elderly-specific trial (and if elderly people are under-represented in clinical trials), some published studies focusing on this topic have shown that, when all patients receive the same treatment, progression and survival rates do not differ between elderly and younger patients (Sequist and Lynch, [2003]). Preliminary regressions of health expenditures and survival as a function of age, among other clinical variables, were ran in order to respectively assess the strength of this instrument in our empirical situation (cf. requirement 1 ) and whether or not the equations of interest would be identifiable.

Our results suggested that both conditions hold when using inpatient length of stay, the number of chemotherapy drugs administered, and the total cost of treatment per day of hospitalisation as proxies of health care expenditures. Indeed, age was significantly correlated to each of these variables but not with survival. Unfortunately, this was not confirmed when using outpatient health care procedures, innovative and expensive chemotherapy drugs, the number of radiotherapy sessions, and the cost of chemotherapy drugs. The instrumental technique was not applicable to these latter cases.

However, the assumption that the instrument (age) was not correlated with the error term in the equation of interest was not testable (requirement 2). In practice, in the first stage, each endogenous covariate (here, each expenditure indicator) was regressed (with a OLS model or with an ordered logistic model, Tobit type I model, or Poisson regression, according the nature of the variable) on all of the exogenous variables. In the second stage, the survival regression was estimated as usual with a Cox model, except that in this stage the endogenous covariate (the considered expenditure) was replaced by the predicted values from the first stage model while the instrument (age) was excluded from the regression. The robust option in Stata was used to give consistent estimates of standard errors, since this method is known to affect the precision of yield estimates. 
- Regarding the survival model as a function of inpatient length of stay, survival was, all other things being equal, significantly worse for patients with stage IV compared to stage IIIB $(p=0.001)$, for patients with adenocarcinoma compared to large cell carcinoma $(p=0.007)$, and for current smokers compared to never smokers $(\mathrm{p}=0.045)$. Survival duration was not significantly associated with inpatient length of stay (Table IV).

- Regarding the survival model as a function of the number of chemotherapy drugs administered, survival was, all other things being equal, significantly worse for patients with stage IV compared to stage IIIB disease $(\mathrm{p}=0.002)$, for those with past or concomitant cardiovascular disease and/or diabetes ( $\mathrm{p}=0.033$ ), and for current smokers compared to never smokers $(p=0.031)$. Survival duration was not significantly associated with the number of chemotherapy drugs administered (Table IV).

- Regarding the survival model as a function of total cost of treatment per day of hospitalisation, survival time was, all other things being equal, significantly shorter for patients with stage IV compared to stage IIIB ( $p=0.003$ ), poor performance status $(p=0.006)$, and past or concomitant cardiovascular and/or diabetes co-morbidities $(\mathrm{p}=0.021)$. Moreover, current smokers had a shorter survival than never smokers $(p=0.03)$. Survival was also significantly shorter for patients with adenocarcinoma compared to large cell carcinoma ( $p=0.003)$, whereas this significance was only borderline for weight loss $(p=0.055)$.

Our results also showed major differences in the significance and magnitude of parameters estimated with and without controlling for endogeneity, leading to opposite conclusions. Survival time was not significantly associated with the number of chemotherapy drugs 
administrated $(p=0.281)$ and total cost of treatment per day of hospitalisation $(p=0.264)$ when using instrumental variables (this finding further confirms the validity of our instrument), as was the case when the original variables were used ( $\mathrm{p}=0.004$ and $\mathrm{p}<0.001$, respectively). These results confirmed our initial suspicion that seriously biased results were obtained when dealing with health expenditures variables, due to reciprocal causation between cost and survival (Table IV).

\section{DISCUSSION}

\section{Choice of the health care expenditure proxies}

Hospitalisation is described in the literature as the most expensive cost item for advanced and metastatic NSCLC (Bordeleau, [2006]). In Dedes et al. study, hospitalisation costs reach 68\% and $74 \%$ of the total costs of treatment in stage III and stage IV patients, respectively, versus only $14 \%$ and $26 \%$ for chemotherapy drugs (Dedes et al., [2004]). Health care expenditures related to hospitalisation are largely integrated in our analysis, e.g. inpatient length of stay, number of outpatient health care procedures, total cost of treatment per day of hospitalisation. Health care expenditures related to chemotherapy drugs are also detailed, e.g. number of chemotherapy drugs administered, number of expensive and innovative chemotherapy drugs administered, total cost of chemotherapy drugs). As radiotherapy can palliate the symptoms of poor-prognosis patients, the number of irradiation sessions was also taken into account (Van den Hout et al., [2006]).

Because this is a retrospective study, rigorously assessing quality of life was not possible. The literature shows low quality of life scores in patients with locally advanced and metastatic NSCLC. Bordeleau reports a score of 0.34 (Bordeleau, [2006]). Van den Hout et al. report a total of $10 \%$ of negative utility measurements, indicating a health state worse than death in 
palliative NCSLC. However, toxicities (e.g. febrile neutropenia, diarrhoea, nausea and vomiting) could be introduced in order to reinforce the present analysis.

\section{A real-life practise study of health care expenditures and survival}

The effect of health care expenditures on survival in locally advanced and metastatic NSCLC was assessed in a real life situation with no previous selection of the patients, contrary to clinical trials. Hence, non surprisingly, the survival results obtained are worse than those of six clinical trials identified by a literature search of Medline for stage IIIB and IV NSCLC since 2000 (Babiak et al., [2007]; Chen et al., [2002]; Galetta et al., [2002]; Perry et al., [2007]; Pujol et al., [2005]; Zinner et al., [2004]). The periods of inclusion of those clinical trials ranged from 1998 to 2001, except for the study reported by A. Babiak et al. which ran from 2002 to 2005 (Babiak et al., [2007]). Except for this study, the median survival reported in clinical trials was higher than in our study. It ranged from 10.5 months (Galetta et al., [2002]) to 17.4 months (Zinner et al., [2004]), compared to 9.6 months in this study.

\section{The necessity to analyse the risk of endogeneity}

Gravelle and Backhouse have highlighted the methodological difficulties associated with empirical investigations in health care, especially the associated endogeneity problem, and the possible time lag between expenditure and outcomes (Gravelle and Backhouse, [1987]). When the estimated regression equation consists of a mixture of potentially endogenous and exogenous variables, the coefficient on the endogenous variables may be biased when studies do not allow for endogeneity (Martin et al, [2008]). The risk of endogeneity and its impact on the relationship between health care expenditures and outcome appear clearly in this study. When endogeneity is not taken into account, the higher the total cost of treatment per day of hospitalisation, the higher the survival rate, and the higher the number of chemotherapy drugs 
administrated, the higher the survival rate. This would lead to the conclusion that health care expenditures have a strong positive effect on survival in patients with advanced or metastatic NSCLC, which would bias the decision-making process in favour of expensive therapies.

\section{Results homogenous with the literature in term of benefit regarding health care expenditures}

Survival time was not significantly associated with either total daily cost or the number of chemotherapy drugs administered and inpatient length of stay. These results reinforce the literature which shows that increasing the number of chemotherapy prescriptions, prolonging cytotoxic therapy, and using innovative and expensive chemotherapy drugs do not significantly improve survival in locally advanced and metastatic NSCLC (Rubio et al., [2002]; Socinsky et al., [2003]). Our results are also in agreement with those of a metaanalysis of 16 trials, which has failed to provide clear evidence of a difference in the effect of chemotherapy between different chemotherapy types or between trials that used combination chemotherapy and those that used single agent chemotherapy (Burdett et al., [2008]).

\section{Implications in term of medical decision-making}

Due to the short survival times observed in advanced or metastatic NSCLC, especially in the "real life situation", to the lack of consequences of health care expenditures on survival as measured by seven proxies, but also, as shown in the literature, to the significant benefit of chemotherapy on survival, the elaboration of recommendations for medical decision-making appears particularly difficult. The American Society for Clinical Oncology recommends, for example, the administration of a combination of two molecules of chemotherapy in first-line,

whereas brief cyto-toxic treatments also appear optimal. Further studies encourage to maintain quality of life and to tailor therapy to patient characteristics and disease specificities 
(age, stage, histology and comorbidities). Based on the present study, we recommend not to multiply chemotherapy drugs and to encourage the use of less expensive drugs. This is particularly important within the French health care system because: (i) Expensive and innovative drugs are reimbursed to the hospitals by the national health insurance in excess of DRG tariffs, while the costs of other chemotherapy drugs are supported by the hospital as part of the DRG. (ii) Clinical phase IV trials are generally not performed. (iii) Cost effectiveness acceptability curves and willingness to pay thresholds are not specified by the French National insurance system.

\section{CONCLUSION}

Although there has been progress in the treatment of NSCLC, survival is still very modest for advanced and metastatic stages. In term of medical-decision making, the present study based on a "real life situation", using several proxies of health care expenditures and controlling the risk for endogeneity, encourages to limit the number of chemotherapy drugs administered and to promote the use of inexpensive drugs. This study also shows the importance of tailoring cytotoxic therapy based, according to the results of survival models, on age, stage, histology and comorbidities. Then, the focus of research on medical decision-making should be on (i) the observation of physicians' behaviour, in particular the reasons why they prescribe non efficient drugs (ii) the preservation of quality of life, based on the results of evaluations of targeted therapies which are pending in lung cancer (Bordeleau, [2006]; Glover et al., [2004]). The mean estimated annual cost of targeted drugs may however reach $\$ 21,963$ for Gefitinib, $\$ 31,000$ for Erlotinib. As targeted cancer drugs are combined with standard regimens, the costs of these drugs add to already costly therapeutic packages. Hence, high-quality evaluations are required to provide clear information on the value and the acceptability of the 
costs of those treatments. Hopefully, targeted therapy could become a favourable option, and a societally viable solution, in advanced and metastatic NSCLC.

\section{Acknowledgment}

We thank the financial and medical information departments of the Léon Bérard Cancer Centre, as well as M-D Reynaud for technical support.

CNIL authorisations: $\mathrm{N}^{\circ} 1257249$

\section{REFERENCES}

Babiak A, Hetzel J, Godde F, Konig HH, Pietsch M, Hetzel M. Mitomycin C and Vinorelbine for second-line chemotherapy in NSCLC-a phase II trial. Br J Cancer. 2007;96(7):1052-6.

Berhoune M, Banu E, Scotte F, Prognon P, Oudard S, Bonan B. Therapeutic strategy for treatment of metastatic non-small cell lung cancer. Ann Pharmacother. 2008;42(11):1640-52.

Billingham LJ, Bathers S, Burton A, Bryan S, Cullen MH. Patterns, costs and costeffectiveness of care in a trial of chemotherapy for advanced non-small cell lung cancer. Lung Cancer. 2002;37(2):219-25.

Bordeleau L. Pharmacoeconomics of systemic therapies for lung cancer. Treat Respir Med. 2006;5(2):129-41. 
Carlson JJ, Veenstra DL, Ramsey SD. Pharmacoeconomic evaluations in the treatment of non-small cell lung cancer. Drugs. 2008;68(8):1105-13.

Cella DF, Patel JD. Improving health-related quality of life in non-small-cell lung cancer with current treatment options. Clin Lung Cancer. 2008;9(4):206-12.

Chen YM, Perng RP, Lee YC, Shih JF, Lee CS, Tsai CM, Whang-Peng J. Paclitaxel plus carboplatin, compared with paclitaxel plus gemcitabine, shows similar efficacy while more cost-effective: a randomized phase II study of combination chemotherapy against inoperable non-small-cell lung cancer previously untreated. Ann Oncol. 2002;13(1):108-15.

Chouaid C, Monnet I, Robinet G, Perol M, Fournel P, Vergnenegre A. Economic impact of gefitinib for refractory non-small-cell lung cancer: a Markov model-based analysis. Curr Med Res Opin. 2007;23(7):1509-15.

Cochrane AL, St Leger AS, Moore F. Health service 'input' and mortality 'output' in developed countries. J Epidemiol Community Health. 1978; 32(3):200-5.

Crémieux PY, Ouellette P, Pilon C. Health care spending as determinants of health outcomes. Health Econ. 1999;8(7):627-39.

Cullen MH, Billingham LJ, Woodroffe CM, Chetiyawardana AD, Gower NH, Joshi R, Ferry DR, Rudd RM, Spiro SG, Cook JE, Trask C, Bessell E, Connolly CK, Tobias J, Souhami RL. 
Mitomycin, ifosfamide, and cisplatin in unresectable non-small-cell lung cancer: effects on survival and quality of life. J Clin Oncol. 1999;17(10):3188-94.

Dedes KJ, Szucs TD, Bodis S, Joerger M, Lowy A, Russi EW, Steinert HC, Weder W, Stahel RA. Management and costs of treating lung cancer patients in a university hospital. Pharmacoeconomics. 2004;22(7):435-44.

Galetta D, Gebbia V, Giotta F, Durini E, Romito S, Borsellino N, Cazzato C, Pezzella G, Colucci G. Gemcitabine and docetaxel every 2 weeks in advanced non-small cell lung cancer: a phase II study of the Grupo oncologica Italia meridionale. Lung Cancer. 2002;38(1):79-84.

Glover KY, Perez-Soler R, Papadimitradopoulou VA. A review of small-molecule epidermal growth factor receptor-specific tyrosine kinase inhibitors in development for non-small cell lung cancer. Semin Oncol. 2004;31(1 Suppl 1):83-92.

Gravelle HS, Backhouse ME. International cross-section analysis of the determination of mortality. Soc Sci Med. 1987;25(5):427-41.

Greene W, 2003. Econometric Analysis 5th edition; Prentice-Hall, Englewood Cliffs, NJ: Pearson Education.

Gridelli C, Aapro M, Ardizzoni A et al. Treatment of advanced non-small-cell lung cancer in the elderly: results of an international expert panel. Journal of clinical oncology 2005;23(13):3125-37. 
Gridelli C, Gallo C, Ceribelli A, Gebbia V, Gamucci T, Ciardiello F, Carozza F, Favaretto A, Daniele B, Galetta D, Barbera S, Rosetti F, Rossi A, Maione P, Cognetti F, Testa A, Di Maio M, Morabito A, Perrone F; GECO investigators. Factorial phase III randomised trial of rofecoxib and prolonged constant infusion of gemcitabine in advanced non-small-cell lung cancer: the GEmcitabine-COxib in NSCLC (GECO) study. Lancet Oncol. 2007 Jun;8(6):50012.

Gujarati D, 2005 Basic Econometrics 4th edition London: McGraw-Hill, Maidenhead, Berks.

Hensing TA, Detterbeck F, Socinski MA. The role of induction therapy in the management of resectable non-small cell lung cancer. Cancer Control. 2000;7(1):45-55.

Lees M, Aristides M, Maniadakis N, McKendrick J, Botwood N, Stephenson D. Economic evaluation of gemcitabine alone and in combination with cisplatin in the treatment of nonsmall cell lung cancer. Pharmacoeconomics 2002;20(5):325-37.

Lichtenberg F. The expanding pharmaceutical arsenal in the war on cancer. NBER Working Paper N¹0328, 2004.

Nolte E, Mc Kee M. Does care save lives? London: The Nuffield Trust, 2004.

Burdett S., NSCLC Meta-Analyses Collaborative Group. Chemotherapy in addition to supportive care improves survival in advanced non-small-cell lung cancer: a systematic review and meta-analysis of individual patient data from 16 randomized controlled trials. J Clin Oncol. 2008; 26(28):4617-25. 
Martin S, Rice N, Smith PC. Does health care spending improve health outcomes? Evidence from English programme budgeting data. J Health Econ. 2008;27(4):826-42.

Perry MC, Kohman LJ, Bonner JA, Gu L, Wang X, Vokes EE, Green MR.A phase III study of surgical resection and paclitaxel/carboplatin chemotherapy with or without adjuvant radiation therapy for resected stage III non-small-cell lung cancer: Cancer and Leukemia Group B 9734. Clin Lung Cancer. 2007;8(4):268-72.

Pujol JL, Breton JL, Gervais R, Rebattu P, Depierre A, Morere JF, Milleron B, Debieuvre D, Castera D, Souquet PJ, Moro-Sibilot D, Lemarie E, Kessler R, Janicot H, Braun D, Spaeth D, Quantin X, Clary C. Gemcitabine-docetaxel versus cisplatin-vinorelbine in advanced or metastatic non-small-cell lung cancer: a phase III study addressing the case for cisplatin. Ann Oncol. 2005;16(4):602-10.

Rebattu P, Quantin X, Ardiet C, Morere JF, Azarian MR, Schuller-Lebeau MP, Pujol JL. Gemcitabine-docetaxel versus cisplatin-vinorelbine in advanced or metastatic non-small-cell lung cancer: a phase III study addressing the case for cisplatin. Lung Cancer. 2001. 33:277287.

Rubio-Terrès C, Tisaire JL, Kobina S, Moyano A. Cost-minimisation analysis of three regimens of chemotherapy (docetaxel-cisplatin, paclitaxel-carboplatin) for advanced nonsmall-cell lung cancer. Lung Cancer. 2002; 35(1):81-9. 
Saint Leger S. The anomaly that finally went away. J Epidemiol Community Health. 2001; 55: 79.

Sequist LV, Lynch TJ. Aggressive treatment for the fit elderly with non-small-cell lung cancer? Yes! Journal of Clinical Oncology 2003; 21 (17): 3186-88.

Socinski MA, Baggstrom MQ, Hensing TA. Duration of therapy in advance metastatic non small cell cancer. Clinical advances in Hematology and Oncology. 2003; 1 (1): 33-38.

Stathopoulos GP, Dafni UG, Malamos NA, Rigatos S, Kouvatseas G, Moschopoulos N. Induction chemotherapy in non small cell lung cancer stage IIIa-b and IV and second-line treatment. Anticancer Res. 1999 Jul-Aug;19(4C):3543-8.

Thongprasert S, Sanguanmitra P, Juthapan W, Clinch J. Relationship between quality of life and clinical outcomes in advanced non-small cell lung cancer: best supportive care (BSC) versus BSC plus chemotherapy. Lung Cancer. 1999;24(1):17-24.

Tigue C, Fitzner K, Alkhatib M, Schmid E, Bennett C. The value of innovation: the economics of targeted drugs for cancer. 2007; Targ. Oncol. 2: 113-119.

Van den Hout W, Kramer GW, Noordijk EM, Leer JW. Cost-utility analysis of short- versus long-course palliative radiotherapy in patients with non-small-cell lung cancer. $J$ Natl Cancer Inst. 2006;98(24):1786-94. 
Vergnenegre A, Combescure C, Fournel P, Bayle S, Gimenez C, Souquet PJ, Lena H, Perol M, Delhoume JY; GFPC (Groupe Français de Pneumo-Cancérologie). Cost-minimization analysis of a phase III trial comparing concurrent versus sequential radiochemotherapy for locally advanced non-small-cell lung cancer (GFPC-GLOT 95-01). Ann Oncol. 2006 ;17(8):1269-74

Young F. An explanation of the persistent doctor mortality association. $J$ Epidemiol Community Health. 2001; 55: 80-84.

Zinner RG, Glisson BS, Fossella FV, Pisters KM, Kies MS, Lee PM, Massarelli E, Sabloff B, Fritsche HA Jr, Ro JY, Ordonez NG, Tran HT, Yang Y, Smith TL, Mass RD, Herbst RS. Trastuzumab in combination with cisplatin and gemcitabine in patients with Her2overexpressing, untreated, advanced non-small cell lung cancer: report of a phase II trial and findings regarding optimal identification of patients with Her2-overexpressing disease. Lung Cancer. 2004;44(1):99-110. 
Table I

Distribution of sociodemographic factors, smoking status and clinicopathologic variables (n=175 patients)

\begin{tabular}{ll}
\hline Characteristics & Mean \pm SD or number of \\
& patients (\%) \\
\hline Age (years) & $59.8 \pm 10.8$ \\
\hline Male / Female & $128(73 \%) / 47(27 \%)$ \\
\hline Tumor stage & $37(21 \%)$ \\
IIIb & $138(79 \%)$ \\
IV & \\
\hline Histology & $82(47 \%)$ \\
Adenocarcinoma & $41(23 \%)$ \\
Epidermoid or malpighian carcinoma & $52(30 \%)$ \\
Large cell carcinoma & $52(24 \%)$ \\
\hline Performance status & $106(60 \%)$ \\
0 & $5(30 \%)$ \\
\hline Normer & \\
\hline
\end{tabular}


Weight loss

Yes

$35(20 \%)$

No

$140(80 \%)$

Past or concomitant cardiovascular disease

and/or diabetes

Yes

$21(12 \%)$

No

154(88\%)

Survival status

Dead

$168(96 \%)$

Alive

$7(4 \%)$

(a) 8 missing data 
Table II

Main resources used

Main resources used

Number of drug administrated

One drug administrated

Two drugs administrated

Three drugs administrated

Four drugs administrated

Five or more

Median [min-max]
$\mathrm{N}^{\circ}$ of patient (\%)

$14(8.0 \%)$

$60(34.3 \%)$

$43(24.6 \%)$

$35(20.0 \%)$

$23(13.1 \%)$

$3[1-8]$

Number of expensive and innovative chemotherapy

drugs

None drug of the list

One drug of the list

$76(43.4 \%)$

Two drugs of the list

$54(30.9 \%)$

Three drugs of the list

$30(17.1 \%)$

Four drugs of the list

Five drugs of the list

$5(2.9 \%)$

Median [min-max]

$2[0-5]$

Inpatient length of stay

Mean ( \pm standard deviation)

$29.0( \pm 26.1)$

Median [min-max]

$25[0-139]$

Number of outpatient health care procedures

Mean ( \pm standard deviation)

$10.7( \pm 11.6)$ 
Number of radiotherapy session administrated ${ }^{(1)}$

None

$\operatorname{Median}^{(1)}$ [min-max]
99 (56.6\%)

14 [1-37] 


\section{Table III}

Average costs (in €)

\section{Costs including zero values}

Costs excluding zero values

\begin{tabular}{|c|c|c|c|c|c|c|c|c|}
\hline & $\mathbf{n}$ & Mean & (SD) & Range & $\mathbf{n}$ & Mean & (SD) & Range \\
\hline Total cost of treatment & 174 & 35,160 & $(24,222)$ & $5,602-131,227$ & & & & \\
\hline Total cost of treatment per day of hospitalisation & 174 & 934 & $(220)$ & $732-1,715$ & & & & \\
\hline Total cost of chemotherapy & 174 & 14,741 & $(14,442)$ & $8-113,668$ & & & & \\
\hline Cost of chemotherapy drugs & 174 & 4,596 & $(5,880)$ & $8-42,705$ & & & & \\
\hline Cost of hospitalisations for chemotherapy & 174 & 10,145 & $(9,477)$ & $0-70,963$ & 162 & 10,901 & $(9,391)$ & 732-70,963 \\
\hline Total cost of chemotherapy per cure & 174 & 1,750 & $(1,367)$ & $8-9,445$ & & & & \\
\hline Total cost of radiotherapy & 175 & 1,741 & $(3,274)$ & $0-22,428$ & 76 & 4,008 & $(3,958)$ & $491-22427$ \\
\hline Cost of sessions & 175 & 1,340 & $(2,076)$ & $0-9,695$ & 76 & 3,085 & $(2,131)$ & $491-9695$ \\
\hline Cost of hospitalisations for radiotherapy & 175 & 401 & $(2,219)$ & $0-19,753$ & 10 & 7,023 & $(6,600)$ & $732-19752$ \\
\hline Total cost of radiotherapy per session & 175 & 117 & (204) & $0-1,495$ & 76 & 270 & $(235)$ & $162-1,495$ \\
\hline Total other costs & 175 & 18,611 & $(18,098)$ & $0-93,642$ & 167 & 19,503 & $(18,051)$ & $732-93,642$ \\
\hline
\end{tabular}




\section{Table IV}

Results of the final survival model as a function of sociodemographic factors, smoking status and clinicopathologic variables, and Health expenditure with and without controlling for endogeneity $(n=173)$

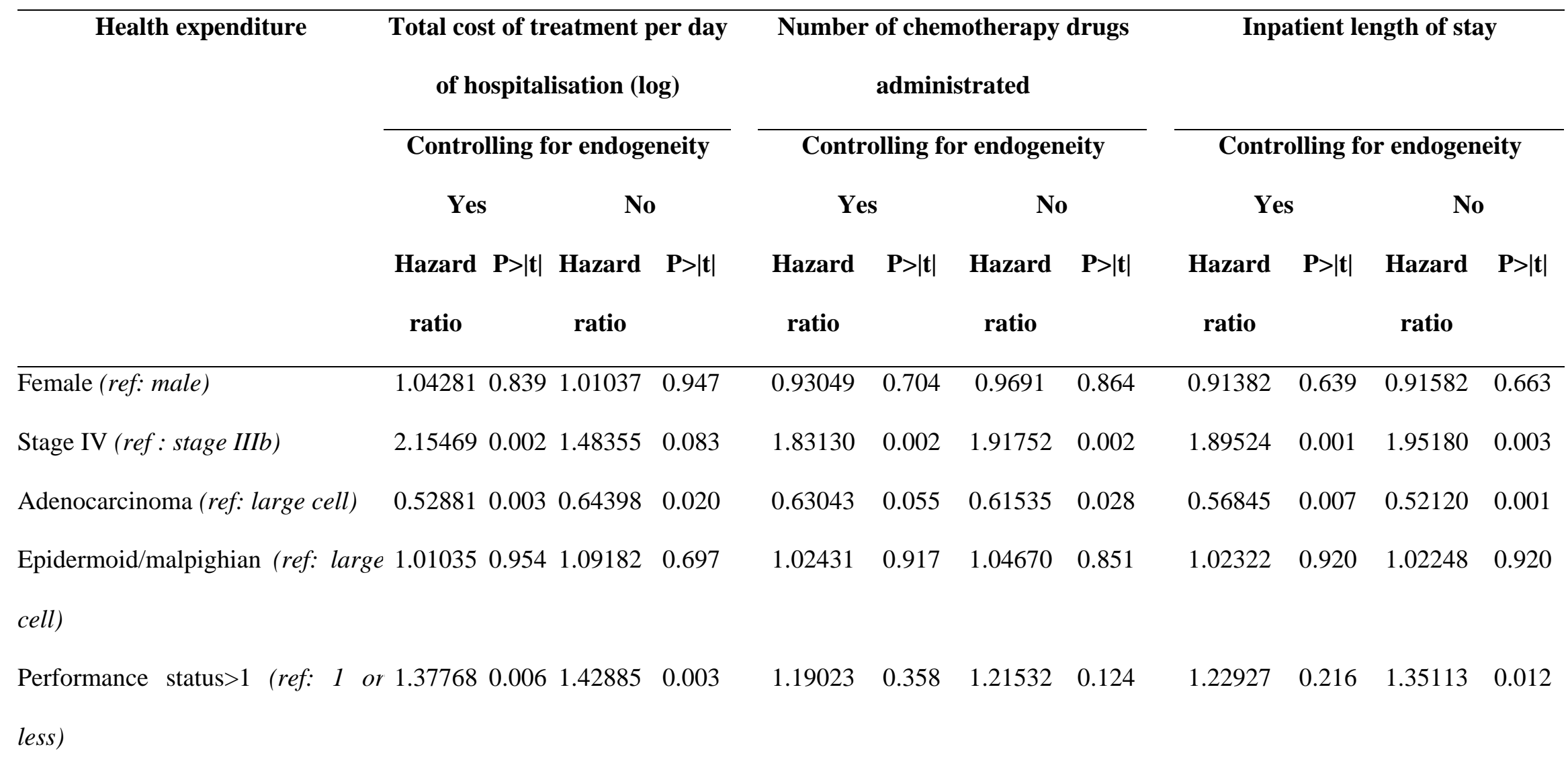




\begin{tabular}{|c|c|c|c|c|c|c|c|c|c|c|c|c|}
\hline Current smoker (ref: never) & 1.55127 & 0.030 & 1.66234 & 0.015 & 1.54897 & 0.031 & 1.46691 & 0.054 & 1.51516 & 0.045 & 1.56880 & 0.029 \\
\hline Former smoker (ref: never) & 1.16595 & 0.527 & 1.40401 & 0.185 & 1.16195 & 0.537 & 1.18953 & 0.434 & 1.07158 & 0.802 & 1.12446 & 0.644 \\
\hline Co-morbidities ( $1=$ yes, $0=$ no) & 1.86777 & 0.021 & 1.54567 & 0.088 & 1.70429 & 0.033 & 1.67673 & 0.047 & 1.54115 & 0.090 & 1.61693 & 0.058 \\
\hline Health expenditure & 8.80018 & 0.264 & 0.15447 & 0.000 & 0.59444 & 0.281 & 0.84212 & 0.004 & 0.98594 & 0.281 & 0.99481 & 0.053 \\
\hline
\end{tabular}

hazards hypothesis 
Figure 1

Kaplan-Meier survival curve stratified by stage

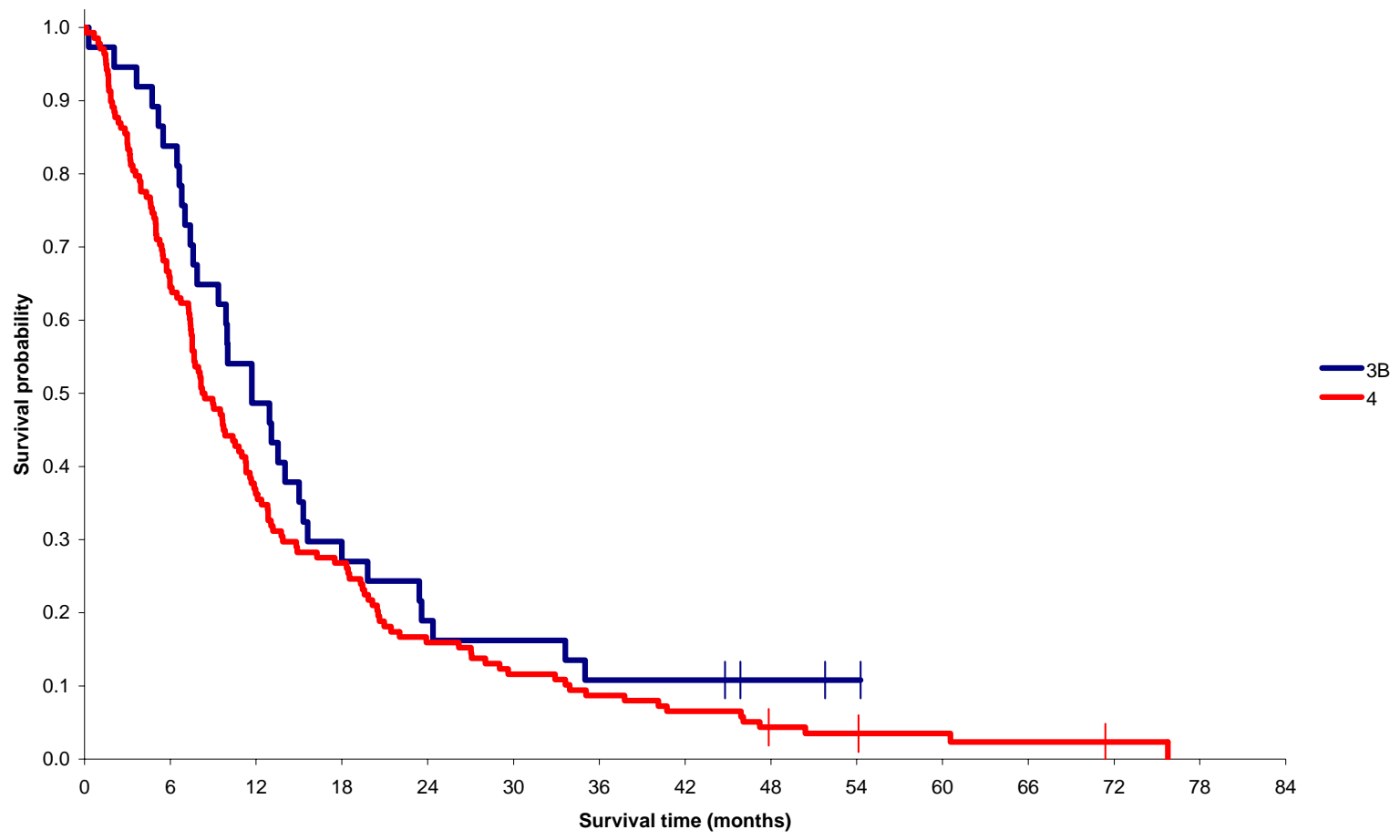

